\title{
ITP Adjuster 1.0: A New Utility Program to Adjust Charges in the Topology Files Generated by the PRODRG Server
}

\author{
Diogo de Jesus Medeiros, ${ }^{1}$ Wilian Augusto Cortopassi, ${ }^{1,2}$ \\ Tanos Celmar Costa França, ${ }^{2}$ and André Silva Pimentel ${ }^{1}$ \\ ${ }^{1}$ Department of Chemistry, Pontifical Catholic University of Rio de Janeiro, Rua Marquês de São Vicente 225, Gávea, \\ 22453-900 Rio de Janeiro, RJ, Brazil \\ ${ }^{2}$ Laboratory of Molecular Modeling Applied to the Chemical and Biological Defense (LMCBD), Military Institute of Engineering, \\ Praça General Tibúrcio, 80, Urca, 22290-270 Rio de Janeiro, RJ, Brazil
}

Correspondence should be addressed to Diogo de Jesus Medeiros; dioginnn@hotmail.com

Received 30 June 2012; Accepted 3 August 2012

Academic Editor: Cristiano R. W. Guimarães

Copyright (C) 2013 Diogo de Jesus Medeiros et al. This is an open access article distributed under the Creative Commons Attribution License, which permits unrestricted use, distribution, and reproduction in any medium, provided the original work is properly cited.

\begin{abstract}
The suitable computation of accurate atomic charges for the GROMACS topology $*$.itp files of small molecules, generated in the PRODRG server, has been a tricky task nowadays because it does not calculate atomic charges using an ab initio method. Usually additional steps of structure optimization and charges calculation, followed by a tedious manual replacement of atomic charges in the $*$.itp file, are needed. In order to assist this task, we report here the ITP Adjuster 1.0, a utility program developed to perform the replacement of the PRODRG charges in the $*$.itp files of small molecules by ab initio charges.
\end{abstract}

\section{Introduction}

The GROMACS package [1] is extensively used for energy minimizations (EM) and molecular dynamics (MD) simulations of biomolecules such as proteins, nucleic acids, peptides, and drugs [2-11]. The input topology files used by GROMACS [1] for small molecules (*.itp files) may be generated by the server PRODRG [12]. However, these files must be adjusted for MD due to the charge group concepts adopted by PRODRG [12].

The topology files preparation for performing EM and MD simulations with GROMACS [1] is very important in investigations of biological processes involving drug interactions with their molecular targets. The force fields available for biomolecules in the literature [13-16] are generally based on macromolecules, such as proteins and nucleic acids, making the preparation of consistent and reliable topology files for small ordinary molecules a challenging task. The PRODRG server [12] is a reliable tool for quickly generating topologies and coordinates of ligands in protein-ligand complexes, using the empirical GROMOS96 force field [14], from a variety of different input files. This tool has been used in several studies and a wide range of knowledge areas [1725]. This server works with the concept of charge groups, which is defined as a group of bonded atoms that sums an integer total charge. Lemkul et al. [26] investigated the quality of topologies generated by the PRODRG server [12] for small molecules for the GROMOS96 43A1 force field [14] and described their functional groups. Their results show that the atomic partial charges are critically incompatible with the GROMOS force fields. Furthermore, when we use the PRODRG [12] parameters, the behavior of the system is notably different than the one observed using the GROMOS parameters. Thus, they suggest a more consistent strategy for the calculation of partial atomic charges, avoiding the deviation of behavior in the system.

Several computer programs are available for structure optimization and charge calculations using quantum chemical calculations [27-29]. The Frisch et al. software [30] has been reported as the most standard for quantum chemical calculations of small molecules [31-33]. Thus, the ITP adjuster 1.0 was built to make the interface of Frisch et al. 
TABLE 1: *.itp files of folic acid before (left) and after (right) applying ITP Adjuster 1.0.

\begin{tabular}{|c|c|c|c|c|c|c|c|c|c|c|c|c|c|c|c|}
\hline $\mathrm{Nr}$ & Type & resnr & resid & Atom & cgnr & Charge & Mass & $\mathrm{Nr}$ & Type & resnr & resid & Atom & cgnr & Charge & Mass \\
\hline 1 & CR1 & 1 & FOL & C15 & 1 & 0.022 & 12.0110 & 1 & CR1 & 1 & FOL & C15 & 1 & 0.113688 & 12.0110 \\
\hline 2 & $\mathrm{HC}$ & 1 & FOL & H15 & 1 & 0.058 & 1.0080 & 2 & $\mathrm{HC}$ & 1 & FOL & H15 & 1 & 0.091572 & 1.0080 \\
\hline 3 & NR & 1 & FOL & N3 & 1 & -0.434 & 14.0067 & 3 & NR & 1 & FOL & N3 & 1 & -0.504841 & 14.0067 \\
\hline 4 & $\mathrm{C}$ & 1 & FOL & $\mathrm{C} 16$ & 1 & 0.335 & 12.0110 & 4 & $\mathrm{C}$ & 1 & FOL & $\mathrm{C} 16$ & 1 & 0.798970 & 12.0110 \\
\hline 5 & NR & 1 & FOL & N6 & 1 & -0.434 & 14.0067 & 5 & NR & 1 & FOL & N6 & 1 & -0.821446 & 14.0067 \\
\hline 6 & $\mathrm{C}$ & 1 & FOL & C19 & 1 & 0.453 & 12.0110 & 6 & $\mathrm{C}$ & 1 & FOL & C19 & 1 & 0.946175 & 12.0110 \\
\hline 7 & NT & 1 & FOL & N7 & 2 & 0.082 & 14.0067 & 7 & NT & 1 & FOL & N7 & 2 & -0.931989 & 14.0067 \\
\hline 8 & $\mathrm{H}$ & 1 & FOL & $\mathrm{H} 72$ & 2 & 0.027 & 1.0080 & 8 & $\mathrm{H}$ & 1 & FOL & $\mathrm{H} 72$ & 2 & 0.414024 & 1.0080 \\
\hline 9 & $\mathrm{H}$ & 1 & FOL & H71 & 2 & 0.027 & 1.0080 & 9 & $\mathrm{H}$ & 1 & FOL & H71 & 2 & 0.433222 & 1.0080 \\
\hline 10 & NR & 1 & FOL & N5 & 2 & 0.061 & 14.0067 & 10 & NR & 1 & FOL & N5 & 2 & -0.786769 & 14.0067 \\
\hline 11 & $\mathrm{H}$ & 1 & FOL & H53 & 2 & 0.027 & 1.0080 & 11 & $\mathrm{H}$ & 1 & FOL & H53 & 2 & 0.414871 & 1.0080 \\
\hline 12 & $\mathrm{C}$ & 1 & FOL & $\mathrm{C} 18$ & 2 & 0.294 & 12.0110 & 12 & $\mathrm{C}$ & 1 & FOL & $\mathrm{C} 18$ & 2 & 0.698881 & 12.0110 \\
\hline 13 & $\mathrm{O}$ & 1 & FOL & $\mathrm{O} 4$ & 2 & -0.676 & 15.9994 & 13 & $\mathrm{O}$ & 1 & FOL & $\mathrm{O} 4$ & 2 & -0.485705 & 15.9994 \\
\hline 14 & $\mathrm{C}$ & 1 & FOL & $\mathrm{C} 17$ & 2 & 0.158 & 12.0110 & 14 & $\mathrm{C}$ & 1 & FOL & $\mathrm{C} 17$ & 2 & -0.275218 & 12.0110 \\
\hline 15 & NR & 1 & FOL & N4 & 3 & -0.619 & 14.0067 & 15 & NR & 1 & FOL & N4 & 3 & -0.194434 & 14.0067 \\
\hline 16 & $\mathrm{C}$ & 1 & FOL & C14 & 3 & 0.127 & 12.0110 & 16 & $\mathrm{C}$ & 1 & FOL & $\mathrm{C} 14$ & 3 & 0.172175 & 12.0110 \\
\hline 17 & $\mathrm{CH} 2$ & 1 & FOL & $\mathrm{C} 13$ & 3 & 0.161 & 14.0270 & 17 & $\mathrm{CH} 2$ & 1 & FOL & $\mathrm{C} 13$ & 3 & 0.134163 & 14.0270 \\
\hline 18 & $\mathrm{~N}$ & 1 & FOL & N2 & 3 & 0.127 & 14.0067 & 18 & $\mathrm{~N}$ & 1 & FOL & $\mathrm{N} 2$ & 3 & -0.476189 & 14.0067 \\
\hline 19 & $\mathrm{H}$ & 1 & FOL & $\mathrm{H} 22$ & 3 & 0.021 & 1.0080 & 19 & $\mathrm{H}$ & 1 & FOL & $\mathrm{H} 22$ & 3 & 0.222443 & 1.0080 \\
\hline 20 & $\mathrm{C}$ & 1 & FOL & $\mathrm{C} 3$ & 3 & 0.127 & 12.0110 & 20 & $\mathrm{C}$ & 1 & FOL & $\mathrm{C} 3$ & 3 & 0.404365 & 12.0110 \\
\hline 21 & CR1 & 1 & FOL & $\mathrm{C} 4$ & 3 & 0.015 & 12.0110 & 21 & CR1 & 1 & FOL & $\mathrm{C} 4$ & 3 & -0.305799 & 12.0110 \\
\hline 22 & $\mathrm{HC}$ & 1 & FOL & $\mathrm{H} 4$ & 3 & 0.041 & 1.0080 & 22 & $\mathrm{HC}$ & 1 & FOL & $\mathrm{H} 4$ & 3 & 0.156776 & 1.0080 \\
\hline 23 & CR1 & 1 & FOL & $\mathrm{C} 5$ & 4 & 0.000 & 12.0110 & 23 & CR1 & 1 & FOL & C5 & 4 & -0.091238 & 12.0110 \\
\hline 24 & $\mathrm{HC}$ & 1 & FOL & H51 & 4 & 0.000 & 1.0080 & 24 & $\mathrm{HC}$ & 1 & FOL & H51 & 4 & 0.118576 & 1.0080 \\
\hline 25 & CR1 & 1 & FOL & $\mathrm{C} 2$ & 4 & 0.000 & 12.0110 & 25 & CR1 & 1 & FOL & $\mathrm{C} 2$ & 4 & -0.334445 & 12.0110 \\
\hline 26 & $\mathrm{HC}$ & 1 & FOL & $\mathrm{H} 21$ & 4 & 0.000 & 1.0080 & 26 & $\mathrm{HC}$ & 1 & FOL & $\mathrm{H} 21$ & 4 & 0.172869 & 1.0080 \\
\hline 27 & CR1 & 1 & FOL & $\mathrm{C} 1$ & 4 & 0.000 & 12.0110 & 27 & CR1 & 1 & FOL & $\mathrm{C} 1$ & 4 & -0.022017 & 12.0110 \\
\hline 28 & $\mathrm{HC}$ & 1 & FOL & H11 & 4 & 0.000 & 1.0080 & 28 & $\mathrm{HC}$ & 1 & FOL & H11 & 4 & 0.106113 & 1.0080 \\
\hline 29 & $\mathrm{C}$ & 1 & FOL & C6 & 4 & 0.000 & 12.0110 & 29 & $\mathrm{C}$ & 1 & FOL & C6 & 4 & -0.147662 & 12.0110 \\
\hline 30 & $\mathrm{C}$ & 1 & FOL & $\mathrm{C} 7$ & 5 & 0.429 & 12.0110 & 30 & $\mathrm{C}$ & 1 & FOL & $\mathrm{C} 7$ & 5 & 0.566722 & 12.0110 \\
\hline 31 & $\mathrm{O}$ & 1 & FOL & $\mathrm{O} 1$ & 5 & -0.612 & 15.9994 & 31 & $\mathrm{O}$ & 1 & FOL & $\mathrm{O} 1$ & 5 & -0.487695 & 15.9994 \\
\hline 32 & $\mathrm{~N}$ & 1 & FOL & N1 & 5 & 0.176 & 14.0067 & 32 & $\mathrm{~N}$ & 1 & FOL & N1 & 5 & -0.654534 & 14.0067 \\
\hline 33 & $\mathrm{H}$ & 1 & FOL & H12 & 5 & 0.030 & 1.0080 & 33 & $\mathrm{H}$ & 1 & FOL & $\mathrm{H} 12$ & 5 & 0.322800 & 1.0080 \\
\hline 34 & $\mathrm{CH} 1$ & 1 & FOL & $\mathrm{C} 8$ & 5 & 0.229 & 13.0190 & 34 & $\mathrm{CH} 1$ & 1 & FOL & $\mathrm{C} 8$ & 5 & 0.290274 & 13.0190 \\
\hline 35 & $\mathrm{C}$ & 1 & FOL & $\mathrm{C} 12$ & 5 & 0.428 & 12.0110 & 35 & C & 1 & FOL & $\mathrm{C} 12$ & 5 & 0.640657 & 12.0110 \\
\hline 36 & $\mathrm{O}$ & 1 & FOL & $\mathrm{O} 3$ & 5 & -0.612 & 15.9994 & 36 & $\mathrm{O}$ & 1 & FOL & $\mathrm{O} 3$ & 5 & -0.499644 & 15.9994 \\
\hline 37 & $\mathrm{OA}$ & 1 & FOL & O6 & 5 & -0.149 & 15.9994 & 37 & OA & 1 & FOL & O6 & 5 & -0.637158 & 15.9994 \\
\hline 38 & $\mathrm{H}$ & 1 & FOL & H6 & 5 & 0.081 & 1.0080 & 38 & $\mathrm{H}$ & 1 & FOL & H6 & 5 & 0.456952 & 1.0080 \\
\hline 39 & $\mathrm{CH} 2$ & 1 & FOL & C9 & 6 & 0.198 & 14.0270 & 39 & $\mathrm{CH} 2$ & 1 & FOL & $\mathrm{C} 9$ & 6 & 0.004713 & 14.0270 \\
\hline 40 & $\mathrm{CH} 2$ & 1 & FOL & $\mathrm{C} 10$ & 6 & 0.198 & 14.0270 & 40 & $\mathrm{CH} 2$ & 1 & FOL & $\mathrm{C} 10$ & 6 & -0.014129 & 14.0270 \\
\hline 41 & $\mathrm{C}$ & 1 & FOL & C11 & 6 & 0.384 & 12.0110 & 41 & C & 1 & FOL & C11 & 6 & 0.703747 & 12.0110 \\
\hline 42 & $\mathrm{O}$ & 1 & FOL & $\mathrm{O} 2$ & 6 & -0.685 & 15.9994 & 42 & $\mathrm{O}$ & 1 & FOL & $\mathrm{O} 2$ & 6 & -0.512801 & 15.9994 \\
\hline 43 & $\mathrm{OA}$ & 1 & FOL & $\mathrm{O} 5$ & 6 & -0.167 & 15.9994 & 43 & $\mathrm{OA}$ & 1 & FOL & O5 & 6 & -0.633904 & 15.9994 \\
\hline 44 & $\mathrm{H}$ & 1 & FOL & H52 & 6 & 0.072 & 1.0080 & 44 & $\mathrm{H}$ & 1 & FOL & H52 & 6 & 0.432867 & 1.0080 \\
\hline
\end{tabular}

[30] with the GROMACS package [1]. However, it may also be easily modified to work with different quantum chemical softwares.

There are several problems to adjust the output files of PRODRG [12] based on Frisch et al. [30] output files (*.out files): (i) the manual edition of the topology charges is an exhausting, tedious, and time-demanding assignment and, so, very susceptible to mistakes; (ii) PRODRG [12] uses a charge group concept, differently from Frisch et al. [30] and any other quantum chemical softwares; (iii) the numbering of hydrogen atoms in the $*$ itp files is incompatible with the output files from quantum chemical softwares; (iv) the bonds 
TABLE 2: *.itp files of cystein before (left) and after (right) applying ITP Adjuster 1.0.

\begin{tabular}{|c|c|c|c|c|c|c|c|c|c|c|c|c|c|c|c|}
\hline $\mathrm{Nr}$ & Type & resnr & resid & Atom & cgnr & Charge & Mass & $\mathrm{Nr}$ & Type & resnr & resid & Atom & cgnr & Charge & Mass \\
\hline 1 & $\mathrm{OA}$ & 1 & CYS & $\mathrm{O} 2$ & 1 & -0.180 & 15.9994 & 1 & $\mathrm{OA}$ & 1 & CYS & $\mathrm{O} 2$ & 1 & -0.553855 & 15.9994 \\
\hline 2 & $\mathrm{H}$ & 1 & CYS & $\mathrm{H} 22$ & 1 & 0.057 & 1.0080 & 2 & $\mathrm{H}$ & 1 & CYS & $\mathrm{H} 22$ & 1 & 0.366426 & 1.0080 \\
\hline 3 & $\mathrm{C}$ & 1 & CYS & $\mathrm{C} 3$ & 1 & 0.372 & 12.0110 & 3 & $\mathrm{C}$ & 1 & CYS & $\mathrm{C} 3$ & 1 & 0.638891 & 12.0110 \\
\hline 4 & $\mathrm{O}$ & 1 & CYS & $\mathrm{O} 1$ & 1 & -0.693 & 15.9994 & 4 & $\mathrm{O}$ & 1 & CYS & $\mathrm{O} 1$ & 1 & -0.478926 & 15.9994 \\
\hline 5 & $\mathrm{CH} 1$ & 1 & CYS & $\mathrm{C} 2$ & 1 & 0.175 & 13.0190 & 5 & $\mathrm{CH} 1$ & 1 & CYS & $\mathrm{C} 2$ & 1 & 0.098300 & 13.0190 \\
\hline 6 & NT & 1 & CYS & N1 & 1 & 0.066 & 14.0067 & 6 & NT & 1 & CYS & N1 & 1 & -0.630975 & 14.0067 \\
\hline 7 & $\mathrm{H}$ & 1 & CYS & H16 & 1 & 0.012 & 1.0080 & 7 & $\mathrm{H}$ & 1 & CYS & H16 & 1 & 0.282228 & 1.0080 \\
\hline 8 & $\mathrm{H}$ & 1 & CYS & H15 & 1 & 0.012 & 1.0080 & 8 & $\mathrm{H}$ & 1 & CYS & H15 & 1 & 0.282036 & 1.0080 \\
\hline 9 & $\mathrm{CH} 2$ & 1 & CYS & $\mathrm{C} 1$ & 1 & 0.153 & 14.0270 & 9 & $\mathrm{CH} 2$ & 1 & CYS & $\mathrm{C} 1$ & 1 & -0.101843 & 14.0270 \\
\hline 10 & $\mathrm{~S}$ & 1 & CYS & $\mathrm{S} 1$ & 1 & 0.077 & 32.0600 & 10 & $S$ & 1 & CYS & $\mathrm{S} 1$ & 1 & 0.049643 & 32.0600 \\
\hline 11 & $\mathrm{H}$ & 1 & CYS & H13 & 1 & -0.051 & 1.0080 & 11 & $\mathrm{H}$ & 1 & CYS & H13 & 1 & 0.048076 & 1.0080 \\
\hline
\end{tabular}

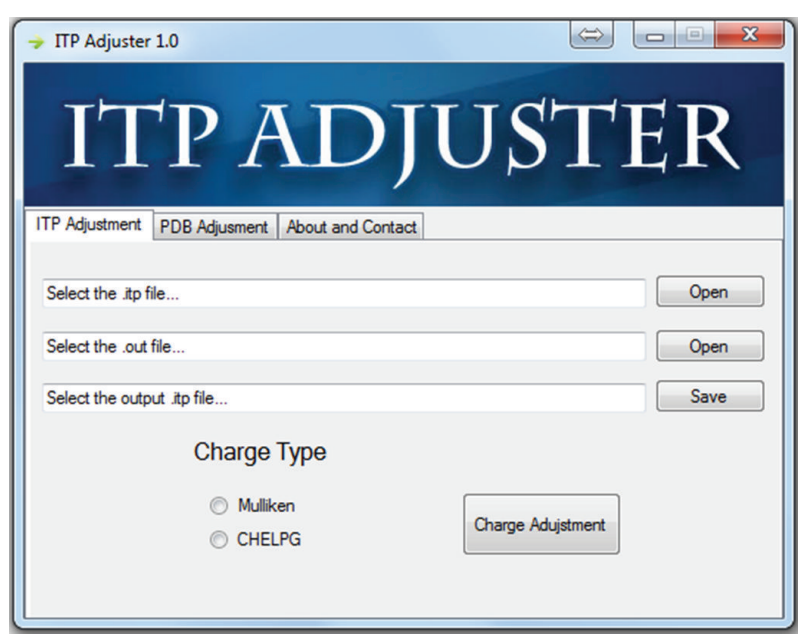

FIgure 1: The ITP Adjuster interface.

information in the Frisch et al. [30] output files may have some inconsistencies, such as hydrogen atoms bonded to two different atoms.

The ITP Adjuster 1.0 (Figure 1) performs a quick and safe edition of the $*$.itp files considering the charge calculations from Frisch et al. [30] using Mulliken or Chelpg (Charges from Electrostatic Potentials) charges. It handles charges of up to six decimal places. At the end of the execution, a message box will inform the total charge of the molecule in the edited $*$.itp file, which may be used as a guide to detect inconsistencies between the $*$.itp and $*$.out files.

\section{Materials and Methods}

2.1. Considerations for Using ITP Adjuster. Some requirements for using the ITP Adjuster 1.0 are important to guarantee its proper installation and use, as discussed below.

ITP Adjuster 1.0 needs the Microsoft.Net Framework 4 or later installed for running properly. The authors recommend the Frisch et al. [30] calculations and PRODRG server [12] topology generation. It is highly desirable to have a *.pdb file with numbered atom names before submitting it to the PRODRG server [12]. It guarantees the correspondence of the atom names between the *.out and the final *.itp files. ITP Adjuster 1.0 also has a functionality named "PDB Adjustment," which verifies a *.pdb file and, if necessary, numbers the atom names.

The hydrogen charges are based on the information of bonds presented in the Frisch et al. [30] output files, which is necessary to provide an $*$.itp file which is compatible with the $*$.out file indicated. An usual mistake occurs when the PRODRG server [12] removes hydrogen atoms from oxygen and nitrogen atoms or adds hydrogen atoms that do not exist in the $*$.out file. In these cases, the user must use the ADDHYD, DELHYD, PATCH, or a combination of these commands in the PRODRG server [12] in order to correct these inconsistencies before using ITP Adjuster 1.0. Not performing this strategy leads to unreliable final $*$.itp files and meaningless total charges.

\section{Results and Discussion}

3.1. Validating ITP Adjuster 1.0. We validated the ITP Adjuster 1.0 with the three common molecules in biological systems: folic acid, adenosine-5' -triphosphate (ATP), and cystein. Structures of these molecules are shown in Figure 2. First we built their 3D structures in the *.pdb format using Gauss View 4.0 and Frisch et al. [30] and submitted them to energy minimization with Frisch et al. [30] using the algorithm B3LYP/3-21G with charge chelpg, in order to generate their $*$.out files. Besides, the $*$.itp files of each molecule were generated at the PRODRG server [12]. The $*$.out and *.itp files were then loaded into the ITP Adjuster 1.0 to change the charges of the $*$ itp files generated by the PRODRG server [12] by using ab initio charges of the *.out files from Frisch et al. [30]. The results are presented in Tables 1, 2, and 3. As it can be seen, the ITP Adjuster 1.0 was able to recognize the atoms in each file. It properly adjusted the charges without modifying the positions of the atoms. The ITP Adjuster 1.0 was also tested against several other small molecules (data not shown) and, without exception, it was able to adjust charges accordingly. 
TABLE 3: *.itp files of ATP before (left) and after (right) applying ITP Adjuster 1.0.

\begin{tabular}{|c|c|c|c|c|c|c|c|c|c|c|c|c|c|c|c|}
\hline $\mathrm{Nr}$ & Type & resnr & resid & Atom & cgnr & Charge & Mass & $\mathrm{Nr}$ & Type & resnr & resid & Atom & cgnr & Charge & Mass \\
\hline 1 & $\mathrm{OA}$ & 1 & ATP & 012 & 1 & -0.256 & 15.9994 & 1 & $\mathrm{OA}$ & 1 & ATP & 012 & 1 & -0.674862 & 15.9994 \\
\hline 2 & $\mathrm{H}$ & 1 & ATP & $\mathrm{H} 12$ & 1 & 0.001 & 1.0080 & 2 & $\mathrm{H}$ & 1 & ATP & $\mathrm{H} 12$ & 1 & 0.395648 & 1.0080 \\
\hline 3 & $\mathrm{P}$ & 1 & ATP & P3 & 1 & 1.081 & 30.9738 & 3 & $\mathrm{P}$ & 1 & ATP & P3 & 1 & 1.542343 & 30.9738 \\
\hline 4 & $\mathrm{OA}$ & 1 & ATP & $\mathrm{O} 13$ & 1 & -0.256 & 15.9994 & 4 & OA & 1 & ATP & $\mathrm{O} 13$ & 1 & -0.731008 & 15.9994 \\
\hline 5 & $\mathrm{H}$ & 1 & ATP & H13 & 1 & 0.001 & 1.0080 & 5 & $\mathrm{H}$ & 1 & ATP & H13 & 1 & 0.418396 & 1.0080 \\
\hline 6 & $\mathrm{OM}$ & 1 & ATP & $\mathrm{O} 7$ & 1 & -0.151 & 15.9994 & 6 & $\mathrm{OM}$ & 1 & ATP & O7 & 1 & -0.606703 & 15.9994 \\
\hline 7 & $\mathrm{OA}$ & 1 & ATP & O6 & 1 & 0.246 & 15.9994 & 7 & $\mathrm{OA}$ & 1 & ATP & O6 & 1 & -0.781970 & 15.9994 \\
\hline 8 & $\mathrm{P}$ & 1 & ATP & $\mathrm{P} 2$ & 1 & 1.081 & 30.9738 & 8 & $\mathrm{P}$ & 1 & ATP & $\mathrm{P} 2$ & 1 & 1.666306 & 30.9738 \\
\hline 9 & $\mathrm{OA}$ & 1 & ATP & O11 & 1 & -0.256 & 15.9994 & 9 & OA & 1 & ATP & O11 & 1 & -0.709606 & 15.9994 \\
\hline 10 & $\mathrm{H}$ & 1 & ATP & H11 & 1 & 0.001 & 1.0080 & 10 & $\mathrm{H}$ & 1 & ATP & H11 & 1 & 0.430751 & 1.0080 \\
\hline 11 & $\mathrm{OM}$ & 1 & ATP & $\mathrm{O} 5$ & 2 & 0.000 & 15.9994 & 11 & $\mathrm{OM}$ & 1 & ATP & $\mathrm{O} 5$ & 2 & -0.656411 & 15.9994 \\
\hline 12 & $\mathrm{OA}$ & 1 & ATP & $\mathrm{O} 4$ & 3 & -0.191 & 15.9994 & 12 & $\mathrm{OA}$ & 1 & ATP & $\mathrm{O} 4$ & 3 & -0.836197 & 15.9994 \\
\hline 13 & $\mathrm{P}$ & 1 & ATP & P1 & 3 & 1.389 & 30.9738 & 13 & $\mathrm{P}$ & 1 & ATP & P1 & 3 & 1.661303 & 30.9738 \\
\hline 14 & $\mathrm{OA}$ & 1 & ATP & $\mathrm{O} 10$ & 3 & -0.199 & 15.9994 & 14 & $\mathrm{OA}$ & 1 & ATP & $\mathrm{O} 10$ & 3 & -0.668092 & 15.9994 \\
\hline 15 & $\mathrm{H}$ & 1 & ATP & $\mathrm{H} 93$ & 3 & 0.001 & 1.0080 & 15 & $\mathrm{H}$ & 1 & ATP & $\mathrm{H} 93$ & 3 & 0.410779 & 1.0080 \\
\hline 16 & $\mathrm{OM}$ & 1 & ATP & $\mathrm{O} 3$ & 4 & -0.177 & 15.9994 & 16 & $\mathrm{OM}$ & 1 & ATP & $\mathrm{O} 3$ & 4 & -0.641581 & 15.9994 \\
\hline 17 & $\mathrm{OA}$ & 1 & ATP & $\mathrm{O} 2$ & 4 & -0.289 & 15.9994 & 17 & $\mathrm{OA}$ & 1 & ATP & $\mathrm{O} 2$ & 4 & -0.604805 & 15.9994 \\
\hline 18 & $\mathrm{CH} 2$ & 1 & ATP & $\mathrm{C} 10$ & 4 & -0.062 & 12.0110 & 18 & $\mathrm{CH} 2$ & 1 & ATP & $\mathrm{C} 10$ & 4 & 0.301881 & 12.0110 \\
\hline 19 & $\mathrm{CH} 1$ & 1 & ATP & $\mathrm{C} 9$ & 4 & 0.093 & 12.0110 & 19 & $\mathrm{CH} 1$ & 1 & ATP & $\mathrm{C} 9$ & 4 & 0.289979 & 12.0110 \\
\hline 20 & $\mathrm{OA}$ & 1 & ATP & $\mathrm{O} 1$ & 4 & -0.289 & 15.9994 & 20 & $\mathrm{OA}$ & 1 & ATP & $\mathrm{O} 1$ & 4 & -0.515384 & 15.9994 \\
\hline 21 & $\mathrm{CH} 1$ & 1 & ATP & $\mathrm{C} 8$ & 4 & 0.024 & 12.0110 & 21 & $\mathrm{CH} 1$ & 1 & ATP & $\mathrm{C} 8$ & 4 & 0.189925 & 12.0110 \\
\hline 22 & $\mathrm{OA}$ & 1 & ATP & $\mathrm{O} 8$ & 4 & -0.301 & 15.9994 & 22 & $\mathrm{OA}$ & 1 & ATP & O8 & 4 & -0.558061 & 15.9994 \\
\hline 23 & $\mathrm{H}$ & 1 & ATP & $\mathrm{H} 82$ & 4 & 0.001 & 1.0080 & 23 & $\mathrm{H}$ & 1 & ATP & $\mathrm{H} 82$ & 4 & 0.358163 & 1.0080 \\
\hline 24 & $\mathrm{CH} 1$ & 1 & ATP & $\mathrm{C} 7$ & 5 & 0.047 & 12.0110 & 24 & $\mathrm{CH} 1$ & 1 & ATP & $\mathrm{C} 7$ & 5 & 0.186587 & 12.0110 \\
\hline 25 & $\mathrm{OA}$ & 1 & ATP & O9 & 5 & 0.261 & 15.9994 & 25 & $\mathrm{OA}$ & 1 & ATP & O9 & 5 & -0.541491 & 15.9994 \\
\hline 26 & $\mathrm{H}$ & 1 & ATP & H92 & 5 & 0.001 & 1.0080 & 26 & $\mathrm{H}$ & 1 & ATP & H92 & 5 & 0.370706 & 1.0080 \\
\hline 27 & $\mathrm{CH} 1$ & 1 & ATP & C6 & 5 & 0.126 & 12.0110 & 27 & $\mathrm{CH} 1$ & 1 & ATP & C6 & 5 & 0.578117 & 12.0110 \\
\hline 28 & NR & 1 & ATP & N3 & 5 & 0.169 & 14.0067 & 28 & NR & 1 & ATP & N3 & 5 & -0.804205 & 14.0067 \\
\hline 29 & CR1 & 1 & ATP & $\mathrm{C} 5$ & 5 & -0.059 & 12.0110 & 29 & CR1 & 1 & ATP & $\mathrm{C} 5$ & 5 & 0.257766 & 12.0110 \\
\hline 30 & $\mathrm{HC}$ & 1 & ATP & $\mathrm{H} 51$ & 5 & -0.023 & 1.0080 & 30 & $\mathrm{HC}$ & 1 & ATP & $\mathrm{H} 51$ & 5 & 0.276650 & 1.0080 \\
\hline 31 & NR & 1 & ATP & $\mathrm{N} 4$ & 6 & -0.499 & 14.0067 & 31 & NR & 1 & ATP & $\mathrm{N} 4$ & 6 & -0.572949 & 14.0067 \\
\hline 32 & $\mathrm{C}$ & 1 & ATP & $\mathrm{C} 3$ & 6 & 0.096 & 12.0110 & 32 & $\mathrm{C}$ & 1 & ATP & $\mathrm{C} 3$ & 6 & 0.176370 & 12.0110 \\
\hline 33 & $\mathrm{C}$ & 1 & ATP & $\mathrm{C} 4$ & 6 & 0.247 & 12.0110 & 33 & $\mathrm{C}$ & 1 & ATP & $\mathrm{C} 4$ & 6 & 0.666733 & 12.0110 \\
\hline 34 & NR & 1 & ATP & $\mathrm{N} 2$ & 6 & -0.512 & 14.0067 & 34 & NR & 1 & ATP & $\mathrm{N} 2$ & 6 & -0.611459 & 14.0067 \\
\hline 35 & CR1 & 1 & ATP & $\mathrm{C} 1$ & 6 & -0.048 & 12.0110 & 35 & CR1 & 1 & ATP & $\mathrm{C} 1$ & 6 & 0.210905 & 12.0110 \\
\hline 36 & $\mathrm{HC}$ & 1 & ATP & $\mathrm{H} 1$ & 6 & -0.019 & 1.0080 & 36 & $\mathrm{HC}$ & 1 & ATP & $\mathrm{H} 1$ & 6 & 0.220957 & 1.0080 \\
\hline 37 & NR & 1 & ATP & N1 & 6 & -0.512 & 14.0067 & 37 & NR & 1 & ATP & N1 & 6 & -0.605878 & 14.0067 \\
\hline 38 & $\mathrm{C}$ & 1 & ATP & $\mathrm{C} 2$ & 6 & 0.247 & 12.0110 & 38 & $\mathrm{C}$ & 1 & ATP & $\mathrm{C} 2$ & 6 & 0.640460 & 12.0110 \\
\hline 39 & NT & 1 & ATP & N5 & 7 & 0.031 & 14.0270 & 39 & NT & 1 & ATP & N5 & 7 & -0.794455 & 14.0270 \\
\hline 40 & $\mathrm{H}$ & 1 & ATP & $\mathrm{H} 53$ & 7 & -0.016 & 1.0080 & 40 & $\mathrm{H}$ & 1 & ATP & $\mathrm{H} 53$ & 7 & 0.327604 & 1.0080 \\
\hline 41 & $\mathrm{H}$ & 1 & ATP & H52 & 7 & -0.015 & 1.0080 & 41 & $\mathrm{H}$ & 1 & ATP & H52 & 7 & 0.336786 & 1.0080 \\
\hline
\end{tabular}

\section{Conclusion}

We reported here the development of the ITP Adjuster 1.0, a utility program built to adjust ab initio charges into $*$.itp files generated by the PRODRG server [12]. This utility program is already in use in our laboratory and proved to be very accurate in the interface of Frisch et al. [30] and GROMACS [1], providing a friendly user interface and a quick way 
<smiles>Nc1nc(O)c2nc(CNc3ccc(C(=O)N[C@@H](CCC(=O)O)C(=O)O)cc3)cnc2n1</smiles><smiles>Nc1ncnc2c1ncn2[C@@H]1O[C@H](O)[C@@H](O)[C@@H](OP(=O)(O)OP(=O)(O)OP(=O)(O)O)[C@H]1O</smiles>

FIGURE 2: Structures of some molecules tested with ATP adjuster 1.0 .

to generate suitable topology files to perform EM and MD calculations with the GROMACS package [1].

This utility program is available free of charge by request at1mm@puc-rio.br.

\section{Conflict of Interests}

All the authors declare that there is no conflict of interests related to the publishing of this paper on the Journal of Chemistry or any direct financial relation with the trademarks mentioned in the paper.

\section{Acknowledgments}

The authors thank the Brazilian funding agencies $\mathrm{CNPq}$ (Grant no. 304187/2009-7), CAPES (Grant no. 02559/099), and FAPERJ (Grant nos. E-26/101.452/2010 and E26-111.532/2008) for financial support. W. A. Cortopassi also thanks CNPq, FAPERJ, the Estudar Foundation, and DMBranco for financial support and fellowship. A. S. Pimentel and T. C. C. Franca are recipients of the FAPERJ Young Scientist of Our State award.

\section{References}

[1] B. Hess, C. Kutzner, D. van der Spoel, and E. Lindahl, "GROMACS 4: algorithms for highly efficient, load-balanced, and scalable molecular simulation," Journal of Chemical Theory and Computation, vol. 4, no. 3, pp. 435-447, 2008.

[2] Q. Wang, N. H. Werstiuk, J. R. Kramer, and R. A. Bell, "Effects of $\mathrm{Cu}$ ions and explicit water molecules on the copper binding domain of amyloid precursor protein APP(131-189): a molecular dynamics study," Journal of Physical Chemistry B, vol. 115, no. 29, pp. 9224-9235, 2011.

[3] K. Ohno, T. Mitsui, Y. Tanida et al., "Docking study and binding free energy calculation of poly (ADP-ribose) polymerase inhibitors," Journal of Molecular Modeling, vol. 17, no. 2, pp. 383-389, 2011.
[4] A. Hung and I. Yarovsky, "Inhibition of peptide aggregation by lipids: insights from coarse-grained molecular simulations," Journal of Molecular Graphics and Modelling, vol. 29, no. 5, pp. 597-607, 2011.

[5] P. Lazar, S. Kim, Y. Lee, and K. W. Lee, “Computational approach to ensure the stability of the favorable ATP binding site in E. coli Hfq," Journal of Molecular Graphics and Modelling, vol. 29, no. 4, pp. 573-580, 2010.

[6] P. Lazar, Y. Lee, S. Kim, M. Chandrasekaran, and K. W. Lee, "Molecular dynamics simulation study for ionic strength dependence of RNA-host factor interaction in Staphylococcus aureus Hfq," Bulletin of the Korean Chemical Society, vol. 31, no. 16, pp. 1519-1526, 2010.

[7] S. J. Irudayam and M. L. Berkowitz, "Influence of the arrangement and secondary structure of melittin peptides on the formation and stability of toroidal pores," Biochimica et Biophysica Acta, vol. 1808, no. 9, pp. 2258-2266, 2011.

[8] R. P. Wesołowski, S. Furmaniak, A. P. Terzyk, and P. A. Gauden, "Simulating the effect of carbon nanotube curvature on adsorption of polycyclic aromatic hydrocarbons," Adsorption, vol. 17, no. 1, pp. 1-4, 2011.

[9] A. J. Beevers and A. Kukol, "Conformational flexibility of the peptide hormone ghrelin in solution and lipid membrane bound: a molecular dynamics study," Journal of Biomolecular Structure and Dynamics, vol. 23, no. 4, pp. 357-364, 2006.

[10] P. Narang, K. Bhushan, S. Bose, and B. Jayaram, "Protein structure evaluation using an all-atom energy based empirical scoring function," Journal of Biomolecular Structure and Dynamics, vol. 23, no. 4, pp. 385-406, 2006.

[11] Y. Tao, Z. H. Rao, and S. Q. Liu, "Insight derived from molecular dynamics simulation into substrate-induced changes in protein motions of proteinase K," Journal of Biomolecular Structure and Dynamics, vol. 28, no. 2, pp. 143-157, 2010.

[12] A. W. Schüttelkopf and D. M. F. van Aalten, "PRODRG: a tool for high-throughput crystallography of protein-ligand complexes," Acta Crystallographica D, vol. 60, no. 8, pp. 1355-1363, 2004.

[13] W. L. Jorgensen and J. Tirado-Rives, "The OPLS potential functions for proteins, energy minimizations for crystals of cyclic peptides and crambin," Journal of the American Chemical Society, vol. 110, no. 6, pp. 1657-1666, 1988.

[14] W. F. van Gunsteren, S. R. Billeter, A. A. Eising et al., "Biomolecular simulation," in The GROMOS96 Manual and User Guide, vdf Hochschulverlag AG an der ETH Zürich and BIOMOS b.v., Groningen, The Netherlands, 1996.

[15] W. D. Cornell, P. Cieplak, C. I. Bayly et al., "A second generation force field for the simulation of proteins, nucleic acids, and organic molecules," Journal of the American Chemical Society, vol. 117, no. 19, pp. 5179-5197, 1995.

[16] S. J. Weiner, P. A. Kollman, D. A. Case et al., "A new force field for molecular mechanical simulation of nucleic acids and proteins," Journal of the American Chemical Society, vol. 106, no. 3, pp. 765-784, 1984.

[17] W. A. Cortopassi, A. A. Oliveira, A. P. Guimarães, M. N. Rennó, A. U. Krettli, and T. C. C. França, "Docking studies on the binding of quinoline derivatives and hematin to Plasmodium falciparum lactate dehydrogenase," Journal of Biomolecular Structure and Dynamics, vol. 29, no. 1, pp. 207-218, 2011.

[18] J. Penna-Coutinho, W. A. Cortopassi, A. A. Oliveira, T. C. C. França, and A. U. Krettli, "Antimalarial activity of potential inhibitors of Plasmodium falciparum lactate dehydrogenase 
enzyme selected by docking studies," PLoS ONE, vol. 6, no. 7, Article ID e21237, 2011.

[19] S. S. Tatke, V. Renugopalakrishnan, and M. Prabhakaran, "Interfacing biological macromolecules with carbon nanotubes and silicon surfaces: a computer modelling and dynamic simulation study," Nanotechnology, vol. 15, no. 10, pp. S684-S690, 2004.

[20] A. W. Schüttelkopf, O. A. Andersen, F. V. Rao et al., "Screeningbased discovery and structural dissection of a novel family 18 chitinase inhibitor," The Journal of Biological Chemistry, vol. 281, no. 37, pp. 27278-27285, 2006.

[21] M. Subashini, P. V. Devarajan, G. S. Sonavane, and M. Doble, "Molecular dynamics simulation of drug uptake by polymer," Journal of Molecular Modeling, vol. 17, no. 5, pp. 1141-1147, 2011.

[22] A. P. Guimarães, A. A. Oliveira, E. F. F. Da Cunha, T. C. Ramalho, and T. C. C. França, "Design of new chemotherapeutics against the deadly anthrax disease. Docking and molecular dynamics studies of inhibitors containing pyrrolidine and riboamidrazone rings on nucleoside hydrolase from Bacillus anthracis," Journal of Biomolecular Structure and Dynamics, vol. 28, no. 4, pp. 455-469, 2011.

[23] A. A. Oliveira, M. N. Rennó, C. A. S. Matos et al., "Molecular modeling studies of yersinia pestis dihydrofolate reductase," Journal of Biomolecular Structure and Dynamics, vol. 29, no. 2, pp. 351-367, 2011.

[24] D. T. Mancini, K. S. Matos, E. F. F. Cunha et al., "Molecular modeling studies on nucleoside hydrolase from the biological warfare agent Brucella suis," Journal of Biomolecular Structure \& Dynamics, vol. 30, pp. 125-136, 2012.

[25] A. P. Guimarães, A. A. Oliveira, E. F. F. da Cunha, T. C. Ramalho, and T. C. C. França, "Analysis of Bacillus anthracis nucleoside hydrolase via in silico docking with inhibitors and molecular dynamics simulation," Journal of Molecular Modeling, vol. 17, pp. 2939-2951, 2011.

[26] J. A. Lemkul, W. J. Allen, and D. R. Bevan, "Practical considerations for building GROMOS-compatible small-molecule topologies," Journal of Chemical Information and Modeling, vol. 50, no. 12, pp. 2221-2235, 2010.

[27] M. W. Schmidt, K. K. Baldridge, J. A. Boatz et al., "General atomic and molecular electronic structure system," Journal of Computational Chemistry, vol. 14, no. 11, pp. 1347-1363, 1993.

[28] M. Valiev, E. J. Bylaska, N. Govind et al., "NWChem: a comprehensive and scalable open-source solution for large scale molecular simulations," Computer Physics Communications, vol. 181, no. 9, pp. 1477-1489, 2010.

[29] J. P. Stewart, "MOPAC, 2009," James Stewart Computational Chemistry, Colorado Springs, CO, USA, 2008, http://OpenMOPAC.net.

[30] M. J. Frisch, G. W. Trucks, H. B. Schlegel et al., Gaussian03 03, Revision C.02, Gaussian03, Inc., Wallingford CT, 2004.

[31] A. S. Christensen, S. P. A. Sauer, and J. H. Jensen, "Definitive benchmark study of ring current effects on amide proton chemical shifts," Journal of Chemical Theory and Computation, vol. 7, no. 7, pp. 2078-2084, 2011.

[32] V. W. Day, M. A. Hossain, O. K. Sung, D. Powell, G. Lushington, and K. Bowman-James, "Encircled proton," Journal of the American Chemical Society, vol. 129, no. 28, pp. 8692-8693, 2007.
[33] L. M. Goldman, D. R. Glowacki, and B. K. Carpenter, "Nonstatistical dynamics in unlikely places: $[1,5]$ Hydrogen migration in chemically activated cyclopentadiene," Journal of the American Chemical Society, vol. 133, no. 14, pp. 5312-5318, 2011. 

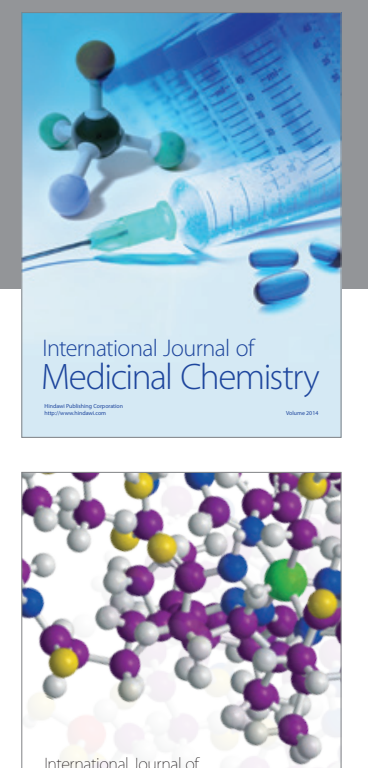

\section{Carbohydrate} Chemistry

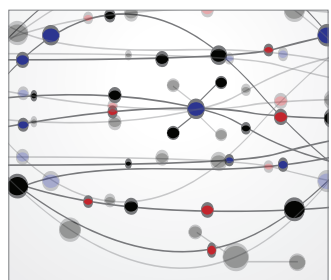

The Scientific World Journal
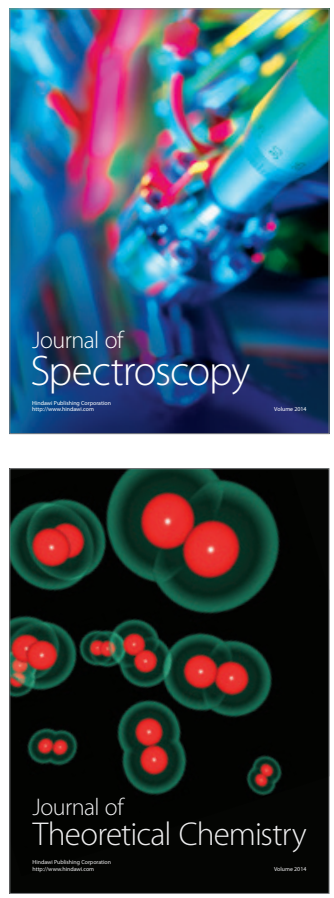
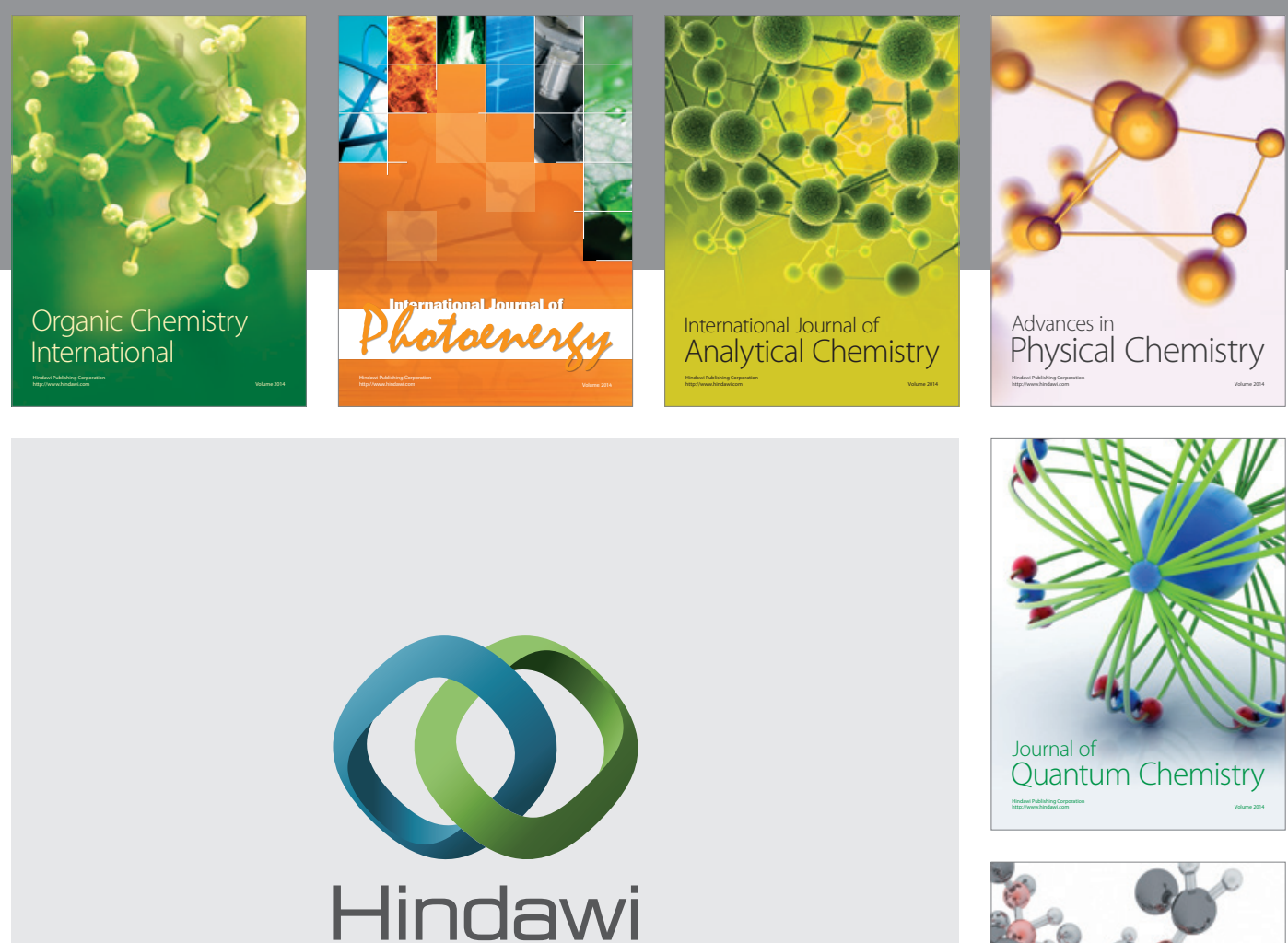

Submit your manuscripts at

http://www.hindawi.com

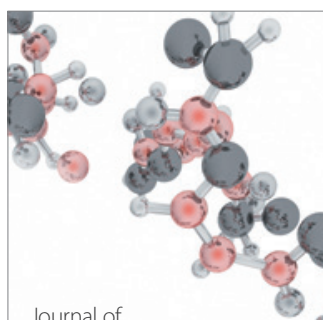

Analytical Methods

in Chemistry

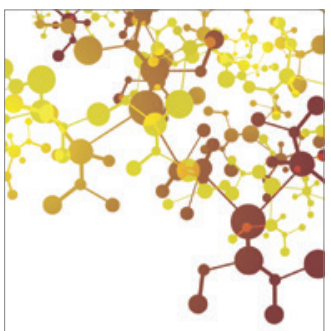

Journal of

Applied Chemistry

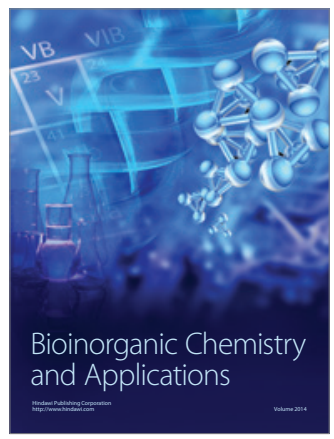

Inorganic Chemistry
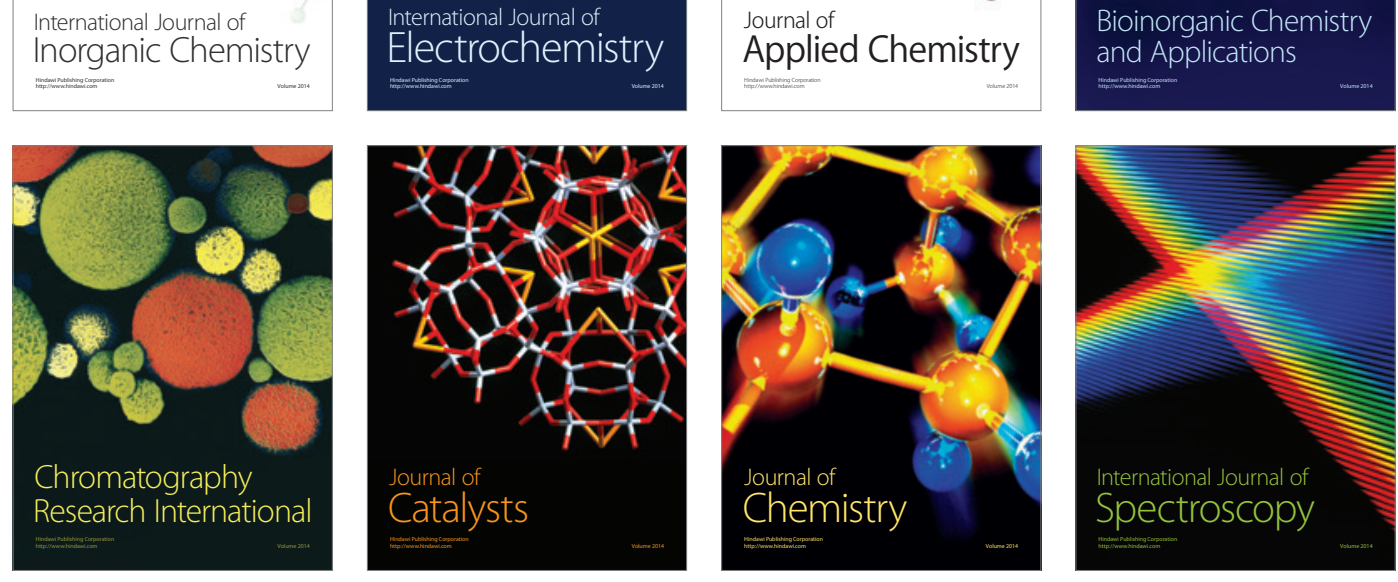